\title{
What is the Current Evidence on Vertebral Body Osteonecrosis?: A Systematic Review of the Literature
}

\author{
Matteo Formica ${ }^{1}$, Andrea Zanirato ${ }^{1}$, Luca Cavagnaro ${ }^{1}$, Marco Basso ${ }^{1}$, \\ Stefano Divano ${ }^{1}$, Carlo Formica ${ }^{2}$, Lamberto Felli ${ }^{1}$ \\ ${ }^{I}$ Department of Orthopaedics, IRCCS Azienda Ospedaliera Universitaria San Martino-IST, Istituto Nazionale per la Ricerca sul Cancro, Genova, Italy \\ ${ }^{2}$ IRCCS Istituto Ortopedico Galeazzi, Milano, Italy
}

Osteonecrosis (ON) is a clinical entity characterized by a pattern of cell death and complex process of bone resorption and formation. Studies related to ON have largely focused on certain anatomical sites; however, the evidence on vertebral body ON (VBON) is largely inconsistent and fragmented. The aim of this study was to clarify the pathophysiology, risk factors, imaging findings, and available treatment modalities for VBON. A systematic review of the relevant articles published in English was performed using PubMed, Embase, Medline, Google Scholar, Cochrane Central Register of Controlled Trials (CENTRAL), and CINAHL databases. A total of 81 articles were included in this study. Three main topics about VBON were identified: (1) pathophysiology and risk factors, (2) diagnosis, and (3) treatment. Forty-five studies were based on the pathophysiology, 52 on diagnosis, and 38 on the treatment options for VBON. The literature on VBON was limited and mainly focused on post-traumatic cases with a considerable overlap with nonunion and pseudoarthrosis.

Keywords: Bone necrosis; Spine; Vertebral body; Diagnosis; Treatment; Outcomes

\section{Introduction}

Osteonecrosis $(\mathrm{ON})$ is a clinical entity characterized by a pattern of cell death and complex process of bone resorption and formation [1]. It has been reported to occur in several locations of the human body, including femoral heads, humeral heads, femoral condyles, distal end of the tibia, vertebral bodies, carpal and tarsal bones, metacarpals, and mandible [2]. Studies related to ON have largely focused on only certain anatomical sites. ON of the femoral head is a well characterized pathology which typically affects relatively young, active people aged $20-40$ years. It has been estimated that 20,000-30,000 new cases of ON are diagnosed annually in the United States [3]. Medication-related ON of the jaw (ONJ) has been widely described in the recent literature. For instance, the risk of ONJ among patients treated for osteoporosis with antiresorptive and antiangiogenic medications has been reported to be approximately $0.1 \%$ [4].

Evidence on vertebral body ON (VBON) is inconsistent and fragmented and mainly limited to post-traumatic cases, with a considerable overlap with nonunion and pseudoarthrosis. The actual incidence of this entity remains

\footnotetext{
Received Mar 31, 2017; Revised May 10, 2017; Accepted May 11, 2017

Corresponding author: Andrea Zanirato

Clinica Ortopedica - IRCCS Azienda Ospedaliera Universitaria San Martino-IST, Istituto Nazionale per la Ricerca sul Cancro, Largo Rosanna Benzi, 1016132 Genova, GE, Italy

Tel: +39-010-5554512, Fax: +39-0105556763, E-mail: dott.zanirato@gmail.com
} 
unknown. An idiopathic etiology for VBON has been usually reported. The affected vertebra is usually located in the lower thoracic or upper lumbar region (T8-L4), owing to the well-known prevalence of vertebral fractures at the thoracolumbar junction. In the majority of cases, only a single vertebra is involved [5]. A correct diagnosis is essential for adequate treatment, and incorrect therapeutic management can lead to adult spinal deformity, neurological deficit, disability, and poor quality of life.

In this study, we intend to clarify the pathophysiology, risk factors, imaging findings, and available treatment modalities for VBON based on a comprehensive review of the literature.

\section{Materials and Methods}

We performed a systematic review of the available English literature on VBON using PubMed, Embase, Medline, Google Scholar, Cochrane Central Register of Controlled Trials (CENTRAL), and CINAHL databases. Combinations of the following keywords were used to retrieve the relevant articles: vertebral body ON, Kümmell's disease (KD), intravertebral vacuum cleft (IVC), diagnosis, treatment, and outcomes. Two reviewers (MF and AZ) independently screened the titles, abstracts, and full texts (when necessary) to identify the eligible studies. Full text reports of the selected studies were included in the analy- sis. Reference lists of the identified articles were manually screened to include all relevant articles. Duplicate publications, review articles, experts' comments, and articles not published in English language were excluded. The included papers were categorized into three groups according to the main topic: (1) pathophysiology and risk factors, (2) diagnosis, and (3) treatment. The level of evidence of a given study was assigned based on the 2005 scoring system adopted by the North American Spine Society [6]. The PRISMA (preferred reporting items for systematic review and meta-analysis) 2009 checklist was followed while performing this review.

\section{Results}

A total of 408 articles were initially retrieved from the databases, of which 85 duplicates were excluded. Finally, 81 articles related to VBON were included in the review: 11 were level III studies, 39 were level IV, and 31 were level II. The article typologies considered for this study included case reports, case series, and retrospective and prospective studies on VBON. Forty-five studies focused on the pathophysiology and risk factors, 52 on the diagnosis, and 38 on the treatment options for VBON. A schematic illustration of the literature search and the study selection criteria are presented in Fig. 1.

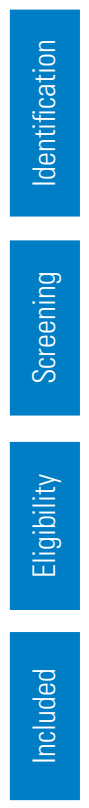

392 Records identified through database searching

16 Additional records identified through other sources

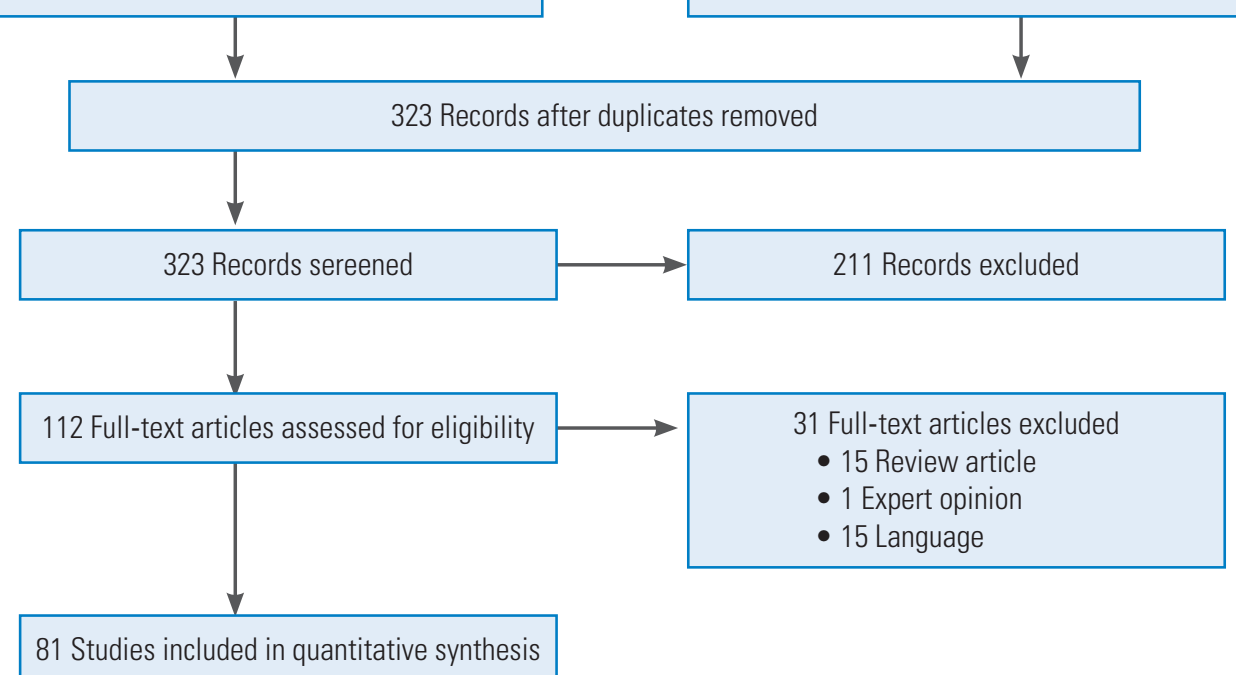

Fig. 1. The PRISMA (preferred reporting items for systematic review and meta-analysis) 2009 flow diagram illustrating the review process. 


\section{Discussion}

\section{Pathophysiology and risk factors}

The most substantial evidence available regarding $\mathrm{ON}$ was with respect to the femoral head; a similar pathological pathway was presumed for $\mathrm{ON}$ at other anatomical sites, such as vertebral bodies. There is a general consensus in the literature about the pathogenesis and histopathology of ON; however, there is no consensus regarding its risk factors. Unfortunately, most reports were anecdotal or employed case-control methods with low level of evidence. Many clinical conditions have been associated with VBON, and several factors may act in combination. Vertebral body necrosis can be caused due to (1) cytotoxicity, (2) genetic factors, and (3) decreased intraosseous blood flow (i.e., ischemia, also known as avascular necrosis [AVN]).

\section{1) Cytotoxicity}

Direct toxic effects on the bone have been described in the literature; e.g., in patients with solid tumors treated with cytotoxic chemotherapy or those with human immunodeficiency virus infection treated with highly active antiretroviral therapy $[7,8]$.

\section{2) Genetic factors}

Some authors hypothesized a protective or predisposing influence of certain genetic factors in the causation of femoral head AVN $[2,9,10]$. However, no such evidence was available for VBON.

\section{3) Ischemia/avascular necrosis}

Ischemia may be related to (1) blood vessel disruption, (2) intraluminal obliteration, or (3) extraluminal obliteration caused due to increased interstitial pressure.

Anatomical studies demonstrated that the posterior two-thirds of vertebral bodies receive collateral blood from four arteries derived from two intervertebral levels, whereas the ventral side does not. Hence, the anterior one-third of the vertebral body is defined by some authors as the "watershed zone" associated with a higher risk of ischemic AVN [11-14].

Post-traumatic vascular disruption is one of the most frequent mechanisms for the development of ON. The possible pathogenesis is based on the interruption or reduction of blood supply consequent to fracture and inadequate revascularization of the bone marrow [2]. Nev- ertheless, there are several notable points. In the literature, trauma and time interval between trauma and ON development have not been clearly defined. Moreover, there is a considerable overlap between various reported clinical entities, such as major or minor trauma in the osteopenic or osteoporotic bone and nonunion caused by instability or vascular damage at the fracture site [5,8,15-28].

In this intricate condition, $\mathrm{KD}$ is also worth mentioning. $\mathrm{KD}$ is a clinical condition in which patients develop a painful progressive angular kyphosis as a result of delayed vertebral body collapse (VBC) after a minor spinal trauma [5,24,29-32]. Kümmell theorized this clinical condition before the advent of radiography $[33,34]$. Only after X-ray examinations were routinely available was $\mathrm{KD}$ recognized as a distinct clinical entity. Steel [33] and Ringler [34] clearly demonstrated that the kyphosis was a consequence of delayed VBC in the absence of radiological evidence of vertebral disruption immediately after trauma [32]. Ideally, $\mathrm{KD}$ is diagnosed on the basis of repeated X-ray examinations, wherein the earliest films do not show any signs of fracture $[29,31,32]$. The actual incidence of the disease is essentially unknown. Currently, AVN is believed to be the main cause of delayed post-traumatic VBC [11].

Interruption of the vascular flow in the vertebral body may result from intravascular obstruction. A variety of conditions may cause intraluminal obliteration. For instance, sickle cell crisis, Caisson disease, and prothrombosis have all been shown to cause VBON $[11,35]$. Pancreatitis is another risk factor for VBON. High blood levels of lipolytic enzymes cause intraosseous fat necrosis and obstruction of bone vessels by fat droplets. Another proposed mechanism is the release of pancreatic enzymes in the abdomen from a cyst [36,37]. Furthermore, arterial abnormalities, dyslipidemia (hypertriglyceridemia), leukemia, and lymphoma have been shown to be associated with a higher risk of $\mathrm{ON}[1,2,38,39]$.

Another mechanism implicated in VBON is extraluminal obliteration of blood vessels caused by increased interstitial pressure. Chronic glucocorticoid therapy and alcohol intake, resulting in fat embolism promotion, lipid deposition, and adipocyte hypertrophy, are also important risk factors reported in the literature [1,2,38-41]. Glucocorticoid therapy is used in a variety of diseases; therefore, it is difficult to discern the contribution of corticosteroids from that of the underlying condition. In Gaucher disease type 1 , the accumulation of glucocerebrosides in histiocytic lysosomes is known to cause increased interstitial 
Table 1. Risk factors for vertebral body osteonecrosis reported in the literature

\begin{tabular}{ll}
\hline Risk factors & \\
\hline Diabetes & Maheshwari et al. [11], Chen et al. [22], Sarli et al. [45], Young et al. [29] \\
\hline Diabetes and hypothyroidism & Ma et al. [31], Swartz and Fee [32] \\
\hline Gaucher disease type 1 & Hermann et al. [42] \\
\hline Human immunodeficiency virus/highly active anti-retroviral therapy & Sifuentes Giraldo et al. [7] \\
\hline Osteopenia/osteoporosis & Kim et al. [15], Lee et al. [19], Kim and Kim [20], Kim et al. [21], Chen et al. [22], \\
& Park et al. [23], Jindal et al. [24], Brower et al. [25], Chou and Knight [26], \\
\hline Osteoporosis and chemotherapy & Mirovsky et al. [27], Fabbriciani et al. [28], Zhang et al. [96] \\
\hline Osteoporosis, dermatomyositis, and azathiprine & Javier et al. [8] \\
\hline Osteoporosis and rheumatic diseases & Martin-Esteve et al. [17] \\
\hline Pancreatitis & Modena et al. [16] \\
\hline Renal disease & Allen et al. [36], Baba et al. [37] \\
\hline Sarcoidosis & Nickell et al. [47] \\
\hline Steroid intake & Ito et al. [46] \\
\hline Steroid intake and temporal arteritis & Wang et al. [39], Osterhouse and Kettner [40], Golimbu et al. [41] \\
\hline
\end{tabular}

pressure $[42,43]$. Furthermore, intramedullary hemorrhage due to trauma or vascular disruption may lead to increased marrow pressure, which in turn may predispose an individual to AVN [44].

Other implicated risk factors for ON have also been reported in the literature but without clear etiopathogenetic mechanism. Diabetes mellitus is a widely reported risk factor for AVN $[11,29,31,32,45]$, probably due to metabolic osteopenia. Ito et al. [46] described the occurrence of $\mathrm{ON}$ in a patient with sarcoidosis. Other predisposing factors include cirrhosis, hyperuricemia, infection, and malignancy [1,47]. Table 1 summarizes the risk factors for VBON reported in the literature.

\section{Diagnosis}

Vertebral biopsy is the gold standard for the diagnosis of ON. Considering the invasiveness of this procedure, imaging should be as accurate as possible. Several imagingbased classification systems for femoral head ON have been developed to facilitate prognostic assessment, treatment planning, and outcome evaluation. These include Ficat-Arlet X-ray classification, Steinberg's system, Association Research Circulation Osseous system, and Japanese Orthopaedic Association system, including computed tomography (CT) and magnetic resonance imaging (MRI) findings. Another staging classification developed by Mitchell et al. [48] relies only on MRI features to estimate the lesion severity. For VBON, no classification system has been widely accepted, and reports about imaging features are generally supported by a low level of evidence.

Maldague et al. [49] described a gaseous collection in the collapsed vertebral body on radiographs. This feature was referred to as IVC, and the authors considered this as a pathognomonic sign of VBON. The cleft can be detected on radiographs as horizontal accumulation of gas (95\% nitrogen, oxygen, and carbon dioxide) and appears as a transverse, linear, or semilunar radiolucent shadow on plain radiographs. In some cases, it appears in extension stress and disappears in flexion $[45,50]$. Some authors suggested that this finding is the result of nonunion due to ischemia and instability after vertebral compression fracture. Other reports have described IVC in the setting of malignancy and infection [27]. Bhalla and Reinus [51] found that linear morphology of vacuum clefts are mostly associated with a benign process and are indicative of ischemic necrosis of the vertebral body. Several synonyms have been used in the literature to describe this feature: "linear intravertebral vacuum" [51], "intravertebral cleft" [52], "intravertebral vacuum phenomenon" [53], "intravertebral vacuum sign" [41], "Kümmell sign" [25], and "intraosseous vacuum phenomenon" [54]. This sign is more easily detected on CT and appears more heterogeneous and irregular than that on X-ray radiographs 
Table 2. Accuracy of imaging findings reported in the literature

\begin{tabular}{|c|c|c|c|c|c|c|c|c|}
\hline Variable & $\begin{array}{l}\text { Sensitivity } \\
(95 \% \mathrm{Cl})\end{array}$ & $\begin{array}{c}\text { Specificity } \\
\text { (95\% CI) }\end{array}$ & $\begin{array}{c}\text { PPV } \\
(95 \% \mathrm{CI})\end{array}$ & $\begin{array}{c}\text { NPV } \\
(95 \% \mathrm{CI})\end{array}$ & $\begin{array}{c}\text { LR+ } \\
(95 \% \mathrm{CI})\end{array}$ & $\begin{array}{c}\text { LR- } \\
(95 \% \text { CI) }\end{array}$ & $\begin{array}{c}\text { DOR } \\
(95 \% \mathrm{CI})\end{array}$ & Reference \\
\hline $\begin{array}{r}\text { IVC (computed } \\
\text { tomography) }\end{array}$ & $85 \%$ & $99 \%$ & $91 \%$ & - & - & - & - & Libicher et al. [55] \\
\hline IVC (MRI) & $\begin{array}{c}50 \% \\
(23 \%-77 \%)\end{array}$ & $\begin{array}{c}67 \% \\
(22 \%-96 \%)\end{array}$ & $\begin{array}{c}78 \% \\
(40 \%-96 \%)\end{array}$ & $\begin{array}{c}36 \% \\
(12 \%-68 \%)\end{array}$ & $\begin{array}{c}1.5 \\
(0.43-5.22)\end{array}$ & $\begin{array}{c}0.75 \\
(0.34-1.62)\end{array}$ & $\begin{array}{c}2 \\
(0.3-14.7)\end{array}$ & Lin et al. [44] \\
\hline Fluid sign (MRI) & $\begin{array}{c}86 \% \\
(57 \%-98 \%)\end{array}$ & $\begin{array}{c}100 \% \\
(54 \%-100 \%)\end{array}$ & $\begin{array}{c}100 \% \\
(70 \%-100 \%)\end{array}$ & $\begin{array}{c}75 \% \\
(36 \%-96 \%)\end{array}$ & $\begin{array}{c}11.7 \\
(0.8-170.3)\end{array}$ & $\begin{array}{c}0.18 \\
(0.06-0.57)\end{array}$ & $\begin{array}{c}65 \\
(2.7-1564)\end{array}$ & Lin et al. [44] \\
\hline
\end{tabular}

$\mathrm{Cl}$, confidence interval; PPV, positive predictive value; NPV, negative predictive value; LR+, positive likelihood ratio; LR-, negative likelihood ratio; DOR, diagnostic odds ratio; IVC, intravertebral vacuum cleft; MRI, magnetic resonance imaging.

[5,29,31,55]. Libicher et al. [56] investigated the prevalence of IVC in vertebral compression fractures using histological evaluation of biopsy specimens from the affected vertebrae. They demonstrated that IVC is a specific indicator of $\mathrm{ON}$ in patients with vertebral compression fractures (sensitivity, $85 \%$; specificity, $99 \%$; positive predictive value, 91\%) and indicated local bone ischemia associated with a nonhealing vertebral collapse and pseudoarthrosis [55]. Others have also supported this theory [52,53,5759]. Another less widely accepted theory hypothesized an intradiscal origin of gas collection in the vertebral body $[60,61]$. However, a retrospective study by Yu et al. [62] suggested that intradiscal gases may originate from the intravertebral body and not vice versa.

Bone scan is among the more sensitive imaging tools for the diagnosis of early ischemic necrosis; however, it is not contemplated as a routine investigation for the diagnostic workup of ON. Van Eenenaam and el-Khoury [38] reported a patient who exhibited increased uptake on bone scintigraphy with normal CT and progressed to VBC in 9 weeks. Contrarily, a recent article described a cold defect on bone scan in a vertebral body with IVC sign [63].

On MRI, IVC generally appears as a hypointense area on T1- and T2-weighted images and exhibits a lack of enhancement on enhanced T1-weighted images. Collection of intravertebral fluid is also described in VBON. This MRI finding is referred as the fluid sign. The fluid collection appears as a well-defined area of low signal intensity on T1-weighted images, high signal intensity on T2-weighted images, and no enhancement on enhanced T1-weighted images $[5,15,24,31,32,44,54,62-69]$. Another MRI finding that is considered highly indicative of AVN is the so-called "double-line sign" (a central zone of hyperintensity surrounded by a hypointense band on T2weighted images) $[11,29,31,32,70,71]$, which has also been described in cases of AVN of the femoral head. This finding is believed to represent the sclerotic tissue surrounding the central new granulation tissue. Some authors have noted that progressive changes in the content of the cleft and consequently in the imaging findings may arise depending on the patients' position [68,72]. Malghem et al. [72] reported that initially, the cleft shows an air pattern during extension of the spine, with a radiolucent band on radiographs and void signal on MRI. Later, the vacuum disappears on radiographs, and a fluid sign appears on T2-weighted images. Furthermore, Yu et al. [62] reported that the occurrence of air and fluid was approximately equal in VBON. The coexistence of air and fluid in the same affected vertebral body is not rare (21.5\%). They also observed that vertebral collapse was significantly more severe in vertebral bodies that had only intravertebral air than in those that had intravertebral fluid with or without air. Additionally, they suggested that intravertebral air represents an advanced stage of the disease, whereas fluid sign may represent an earlier stage [62]; this hypothesis has been supported by Lin et al. [44] in a recent article. They also speculated that patients with a fluid sign are more prone to developing bone regeneration than those with no fluid sign and that fluid sign is a stronger indicator of ON than intravertebral vacuum phenomenon (diagnostic odds ratio, 65 versus 2 ; sensitivity, $86 \%$ versus $50 \%$; specificity, $100 \%$ versus $67 \%$ ) [44]. Conversely, in a retrospective comparative study by Niu et al. [73], vertebral height restoration and kyphotic deformity correction in patients with intravertebral air was significantly better than that in patients with fluid sign. Table 2 describes the accuracy of imaging findings reported in the literature.

Considering the lack of a classification system and based on the evidence drawn from our review about the diagnosis of VBON, we propose a classification based on the 
Table 3. Proposal of novel VBON classification according to relevant imaging findings and sagittal biomechanical parameters

\begin{tabular}{|c|c|}
\hline Variable & VBON classification [74] \\
\hline \multicolumn{2}{|l|}{ Stage } \\
\hline Stage 0 & $\begin{array}{l}\text { Findings: no } \\
\text { Diagnostic techniques: } \mathrm{X} \text {-ray, CT, bone scan, and MRI (negative) }\end{array}$ \\
\hline Stage 1 & $\begin{array}{l}\text { Findings: edema } \\
\text { Diagnostic techniques: X-ray and CT (negative); bone scan and MRI (positive) }\end{array}$ \\
\hline Stage 2 & $\begin{array}{l}\text { Findings: fluid sign, vacuum sign, double-line sign } \\
\text { Diagnostic techniques: } \mathrm{X} \text {-ray, CT, bone scan, and MRI (positive) }\end{array}$ \\
\hline Stage 3 & $\begin{array}{l}\text { Findings: fixed deformity } \\
\text { Diagnostic techniques: bone scan and MRI (negative); X-ray and CT (positive) }\end{array}$ \\
\hline \multicolumn{2}{|l|}{ Modifiers $^{\text {a) }}$} \\
\hline \multicolumn{2}{|c|}{ Angular kyphosis } \\
\hline A & Anterior/posterior wall height ratio $>75 \%$ \\
\hline B & Anterior/posterior wall height ratio $<75 \%$ \\
\hline \multicolumn{2}{|c|}{ Sagittal balance ${ }^{\text {b) }}$} \\
\hline 1 & SVA $<50 \mathrm{~mm} ; \mathrm{PT} \leq \mathrm{thPT}^{\mathrm{c})}$ \\
\hline 2 & SVA $<50$ mm; PT $>$ thPT \\
\hline 3 & SVA >50 mm; PT >thPT \\
\hline
\end{tabular}

General rule: stage+angular kyphosis modifier+sagittal balance modifier=classification (i.e., stages 2, A, 1).

VBON, vertebral body osteonecrosis; CT, computed tomography; MRI, magnetic resonance imaging; SVA, sacral vertical axis; PT, pelvic tilt; thPT, theoretical pelvic tilt.

${ }^{\text {al }}$ Modifiers are not applicable for stage 0 and $1 .{ }^{\text {b) }}$, balance; 2 , hidden imbalance; 3 , imbalance. ${ }^{c / t h P T}=-7+0.37 \times$ pelvic incidence; according to Vialle formula [74].

imaging findings and sagittal parameters that may provide a basis for staging and treatment of VBON [74] (Table 3).

\section{Treatment}

Several factors must be considered when defining the most suitable treatment modality for VBON, including comorbidity, levels of pain and disability, time from onset, spinopelvic balance, and possible neurological involvement. Sagittal balance has been increasingly considered in the last decade. Sagittal plane alignment is closely associated with disability and quality of life, whereas coronal imbalance has a minor impact on clinical outcomes. An adequate radiological evaluation with posteroanterior and lateral full-length radiographs is mandatory prior to deciding the treatment option (surgical versus conservative approach). The vertebral surgeon must evaluate the pelvic parameters (pelvic incidence [PI], pelvic tilt [PT], and sacral slope) and sagittal alignment (lumbar lordosis [LL], thoracolumbar kyphosis [TLK], thoracic kyphosis [TK], and sacral vertical axis [SVA]). PI is the key parameter for the evaluation of global spinopelvic balance; using PI, it is possible to cal- culate the theoretical values of PT, LL, and TK for each patient. General alignment goals have also been established: SVA $<50 \mathrm{~mm}, \mathrm{PT} \leq$ theoretical PT (thPT $=0.37 \times \mathrm{PI}-7)$, TLK $=0^{\circ}$, and LL angle $>10^{\circ}$ of PI [75]. The most common sagittal anomalies included hypolordosis or kyphosis in the lumbar spine, kyphosis in the thoracolumbar junction, and hyperkyphosis in the thoracic spine.

Sagittal alignment can be classified into balanced (SVA $<50 \mathrm{~mm}$ and $\mathrm{PT} \leq$ thPT), compensating (hidden imbalance, $\mathrm{SVA}<50 \mathrm{~mm}$ and $\mathrm{PT}>$ thPT), and imbalanced (SVA $>50 \mathrm{~mm}$ and $\mathrm{PT}>$ thPT) profiles. Lamartina and Berjano [76] recently proposed a classification for sagittal imbalance based on sagittal alignment and compensatory mechanism [75,77]. As far as VBON treatment is concerned, a spectrum of options have been described in the literature (Table 4).

\section{Conservative management}

Early reports in the literature focused on conservative treatments, such as bracing and bed rest, whereas more recent ones favored surgical intervention $[33,38]$. Adju- 
Table 4. Summary of the main surgical treatment options and related findings

\begin{tabular}{|c|c|c|c|}
\hline Surgical technique & Main findings & Reference & $\begin{array}{l}\text { Level of } \\
\text { evidence }\end{array}$ \\
\hline \multirow[t]{14}{*}{ Vertebroplasty } & An effective treatment option & Do et al. [80] & IV \\
\hline & & Hirsch et al. [83] & V \\
\hline & & Jang et al. [18] & IV \\
\hline & & Kim et al. [86] & III \\
\hline & & Kim et al. [15] & IV \\
\hline & & Peh et al. [81] & IV \\
\hline & $\begin{array}{l}\text { Risk of cement leakage in vertebral body } \\
\text { osteonecrosis }\end{array}$ & Cho et al. [106] & V \\
\hline & & Ha et al. [91] & III \\
\hline & & Nieuwenhuijse et al. [90] & IV \\
\hline & IVC and lower risk of cement leakage & Krauss et al. [89] & III \\
\hline & $\begin{array}{l}\text { Treatment option but associated with recur- } \\
\text { rent kyphosis }\end{array}$ & Fang et al. [57] & IV \\
\hline & & Heo et al. [95] & IV \\
\hline & $\begin{array}{l}\text { Similar incidence of cement leakage with } \\
\text { and without IVC }\end{array}$ & Jung et al. [94] & III \\
\hline & & Tanigawa et al. [92] & IV \\
\hline \multirow[t]{4}{*}{ Kyphoplasty } & An effective treatment option & Chen et al. [85] & IV \\
\hline & & Huang et al. [84] & IV \\
\hline & & Yang et al. [82] & IV \\
\hline & $\begin{array}{l}\text { Fluid sign related to better kyphosis correc- } \\
\text { tion than vacuum sign }\end{array}$ & Niu et al. [74] & III \\
\hline \multirow[t]{2}{*}{ Vertebroplasty vs. kyphoplasty } & Similar incidence of cement leakage & Wu et al. [93] & IV \\
\hline & Similar clinical and radiological results & Zhang et al. [88] & III \\
\hline \multirow[t]{3}{*}{ Vertebroplasty+short segmental fixation } & Treatment option & Lee et al. [19] & IV \\
\hline & & Li et al. [98] & IV \\
\hline & & Zhang et al. [96] & IV \\
\hline $\begin{array}{l}\text { Vertebroplasty+posterior fixation with bone cement- } \\
\text { augmented screws }\end{array}$ & Treatment option & Kim and Kim [20] & V \\
\hline Kyphoplasty vs. vertebroplasty+short segmental fixation & Similar results & Chen et al. [22] & III \\
\hline \multirow[t]{2}{*}{ Intracorporal bone graft+posterior fixation } & Effective treatment & Chen et al. [54] & IV \\
\hline & $\begin{array}{l}\text { Treatment option but associated with recur- } \\
\text { rent kyphosis }\end{array}$ & Lee et al. [97] & IV \\
\hline Posterior fixation with bone cement-augmented screws & Effective treatment option & Park et al. [23] & IV \\
\hline Vertebral column resection+posterior fixation & Treatment option & Lee et al. [103] & V \\
\hline $\begin{array}{l}\text { Transpedicular subtraction and disc osteotomy+long seg- } \\
\text { ment fixation }\end{array}$ & Treatment option & Zhang et al. [102] & IV \\
\hline
\end{tabular}

IVC, intravertebral vacuum cleft.

vant therapeutic tools, such as bisphosphonates, teriparatide, and capacitive coupling electrical stimulation, have been proposed in the literature $[28,78]$.

\section{Vertebral augmentation techniques}

Percutaneous vertebral augmentation is a widely performed technique (vertebroplasty, kyphoplasty, and 
craniocaudal expandable device with consecutive bone cement injection) $[15,18,71,79-87]$ aimed at pain relief, restoration of the vertebral body height, and correction of the deformity (Figs. 2-4). Zhang et al. [88] reported similar clinical and radiological outcomes of kyphoplasty and vertebroplasty. Vertebroplasty is less expensive, whereas

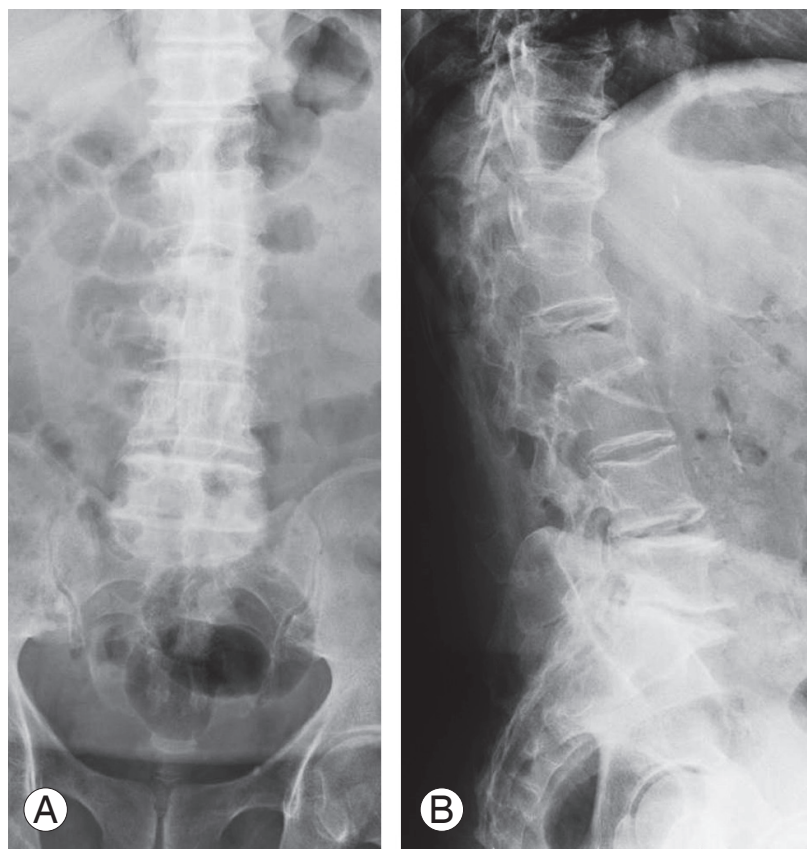

Fig. 2. (A, B) X-ray image of an 81-year-old male patient after 5 months of brace treatment for A1 ASIA (American Spinal Injury Association) E L2 vertebral fracture staged as 2, A, 3 according to our classification. The image shows intravertebral vacuum cleft compatible with vertebral body osteonecrosis. The patient suffered from uncontrolled back pain with significantly impaired quality of life. kyphoplasty is associated with a lower risk of cement leakage [88]. Patients with IVC achieved better kyphosis angle reduction with percutaneous vertebral augmentation than those without IVC [89]. Various studies that examined the correlation between the presence of IVC and cement leakage have yielded conflicting results. Krauss et al. [89] reported a lower incidence in cases with IVC, whereas others identified IVC as an additional strong risk factor for cement leakage [90,91]. Tanigawa et al. [92], Wu et al. [93], and Jung et al. [94] found no statistically significant association between IVC and cement leakage. Heo et al. [95] observed that after vertebroplasty, the compression and kyphosis of VBON continued to progress for $\geq 2$ years. As vertebroplasty may not provide sufficient stability, they strongly recommended strict observation and follow-up. It is also possible to use a combination of pedicle screw fixation in the adjacent levels and percutaneous vertebral augmentation at the necrotic level to improve stability $[19,20,22,23,96]$.

\section{Major surgical management}

The amount of necessary sagittal correction significantly determines the choice of surgical strategy. Surgeons must provide an adequate frame to the anterior column and sufficient instrumentation to the posterior column to support the correction until a solid fusion occurs. Surgical approach, either in one or two stages, can be performed only with a posterior, anterior, or lateral approach as well as with a combined anterior-posterior and lateral-pos-
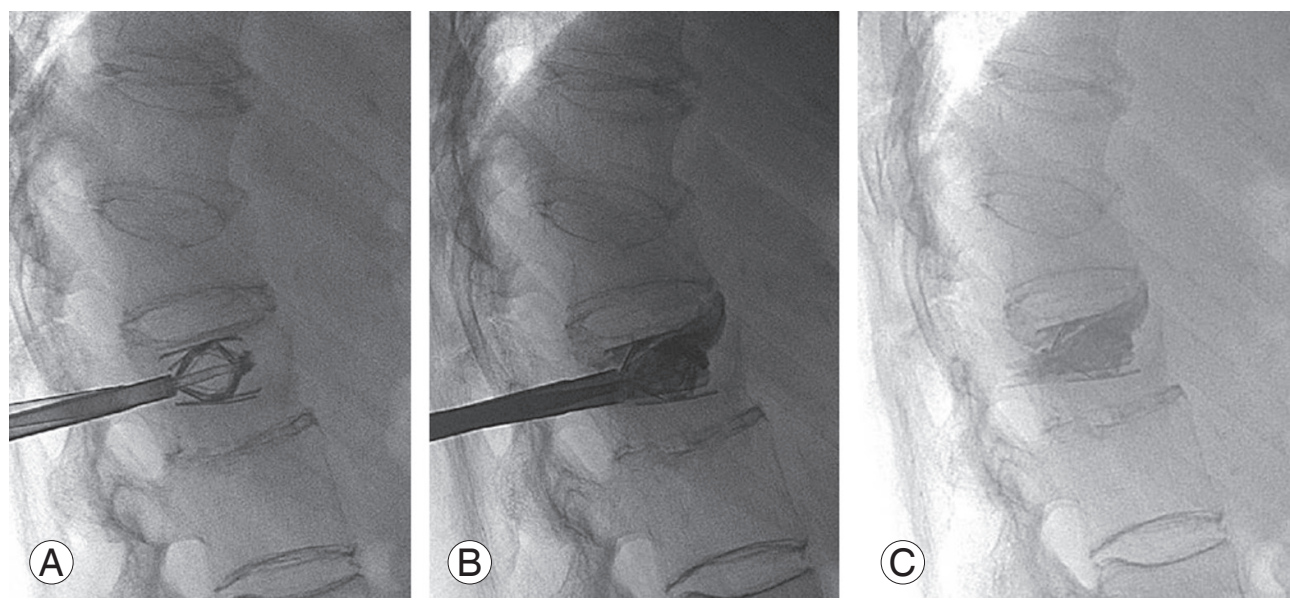

Fig. 3. (A-C) Intraoperative images during vertebral augmentation. For high perioperative risk (American Society of Anesthesiologists 5), the surgeon opted for a bilateral transpedicular percutaneous craniocaudal expandable device to restore the original vertebral shape and bone cement injection to stabilize the reduction. 

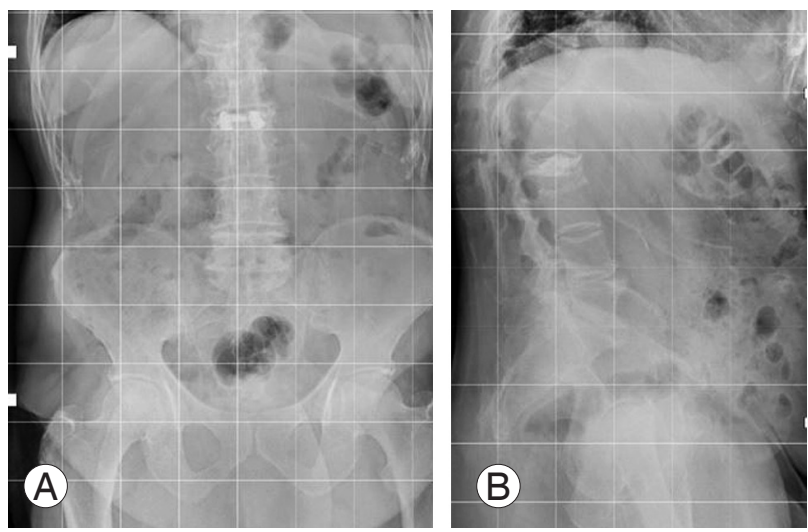

Fig. 4. (A, B) Postoperative X-rays. The patient reported pain relief and improvement in the quality of life.
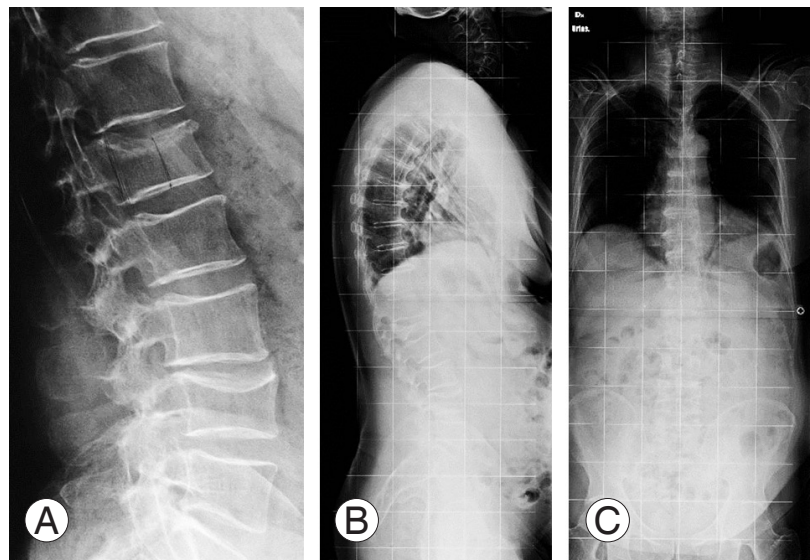

Fig. 5. (A) X-ray image at emergency department admission of a 70-year-old male misdiagnosed with A3 ASIA (American Spinal Injury Association) E L1 vertebral fracture. (B, C) X-ray images after 2 months of bracing treatment.

terior approach. However, some authors recommended a purely posterior approach in high-risk patients, such as the elderly and those with comorbidities, to avoid potential complications associated with the violation of the thoracic cavity or retroperitoneal space.

Osteoporosis is the most common comorbidity in patients with VBON, and a high rate of implant failure has been reported due to decreased bone strength and density. Augmentation methods to enhance pedicle screw fixation have improved, including instrumentation at multiple levels, bioactive cement augmentation, use of fenestrated or expandable pedicle screws [20], and sublaminar clamps and hooks to improve the stability of fusion. Posterior transpedicular vertebral bone grafting with pedicle screw fixation is another treatment option reported in the literature, although with contrasting results $[39,54,97,98]$. In most cases, prompt diagnosis of vertebral fracture can
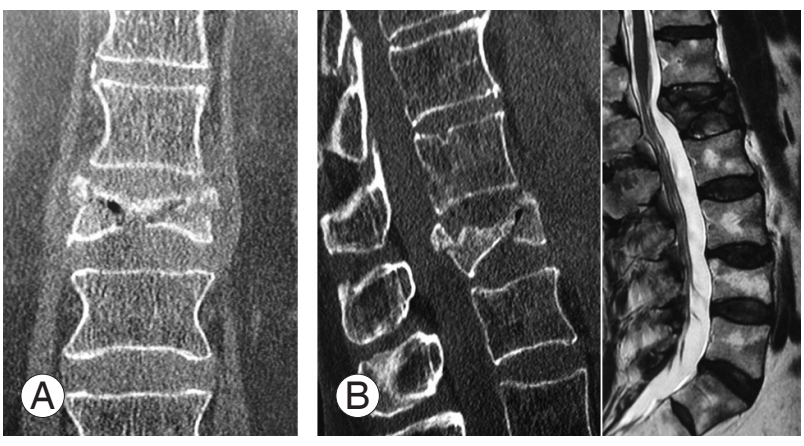

Fig. 6. (A, B) Computed tomography at 2 months after trauma confirmed severe L1 vertebral body collapse (type A3) with vertebral body osteonecrosis and intravertebral vacuum cleft sign. (C) Magnetic resonance imaging T2-weighted image shows hypointense lesion at L1 vertebral body.
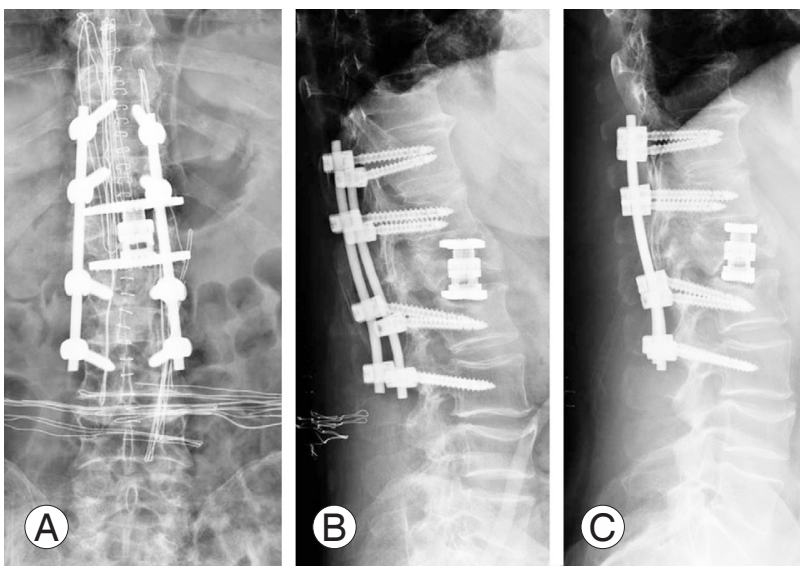

Fig. 7. (A-C) X-ray image after corpectomy at the vertebral body osteonecrosis level and posterior fusion (T11-L3).

help prevent VBON, fix the deformity, and preclude the need for radical correction methods $[30,99,100]$.

The most common osteotomies for the correction of sagittal imbalance are Smith-Petersen osteotomy in the lumbar spine, Ponte's osteotomy in the thoracic spine, pedicle subtraction osteotomy (PSO), asymmetrical PSO in the presence of coronal imbalance, and Corner osteotomy $[101,102]$. In case of notable insufficiency of the anterior column, vertebral column resection (VCR) with the use of an expansible cage is recommended [102] (Figs. 5-7). However, these surgical techniques are associated with high rates of complications. In a recent review, the authors reported a total incidence of complications of $66 \%$ for PSO, 35\% for VCR, and 45\% for non-three column osteotomy [103-106]. 


\section{Conclusions}

To the best of our knowledge, this is the first systematic review that summarizes the available evidence related to the pathophysiology, risk factors, imaging findings, and available treatments for $\mathrm{VBON}$.

The number of studies on VBON is limited, somewhat inconsistent, often limited to certain anatomical sites, and mainly focused on post-traumatic cases, with a considerable overlap with nonunion and pseudoarthrosis. Considering this limitation, the main reported risk factors include osteopenia/osteoporosis and steroid therapy; however, several factors can act in combination. The lack of high-grade evidence makes it difficult to clearly identify the optimal diagnostic protocol and treatment guidelines for patient management. The dualism between air and fluid clefts remains unclear and controversial. The present study suggested that further high quality research and treatment-oriented classification are needed to better understand and treat this common but unclear clinical entity.

\section{Conflict of Interest}

No potential conflict of interest relevant to this article was reported.

\section{Acknowledgments}

We gratefully acknowledge H2O S.R.L. for the English version of this manuscript.

\section{References}

1. Shah KN, Racine J, Jones LC, Aaron RK. Pathophysiology and risk factors for osteonecrosis. Curr Rev Musculoskelet Med 2015;8:201-9.

2. Lafforgue P. Pathophysiology and natural history of avascular necrosis of bone. Joint Bone Spine 2006;73:500-7.

3. Moya-Angeler J, Gianakos AL, Villa JC, Ni A, Lane JM. Current concepts on osteonecrosis of the femoral head. World J Orthop 2015;6:590-601.

4. Rosella D, Papi P, Giardino R, Cicalini E, Piccoli L, Pompa G. Medication-related osteonecrosis of the jaw: clinical and practical guidelines. J Int Soc Prev Community Dent 2016;6:97-104.
5. Li H, Liang CZ, Chen QX. Kummell's disease, an uncommon and complicated spinal disorder: a review. J Int Med Res 2012;40:406-14.

6. North American Spine Society. Levels of evidence for primary research question [Internet]. Burr Ridge (IL): North American Spine Society; 2005 [cited 2017 Mar 20]. Available from: https://www.spine.org/Documents/ResearchClinicalCare/LevelsOfEvidence.pdf.

7. Sifuentes Giraldo WA, Macia Villa CC, RodriguezNavarro CQ, Vazquez Diaz M. Vertebral osteonecrosis in an HIV-infected patient. Antivir Ther 2012;17:1627-30.

8. Javier RM, Moser T, Dietemann JL, et al. Multiple vertebral osteonecrosis. Joint Bone Spine 2008;75:341-4.

9. Pouya F, Kerachian MA. Avascular necrosis of the femoral head: are any genes involved? Arch Bone Jt Surg 2015;3:149-55.

10. Zhou ZC, Gu SZ, Wu J, Liang QW. VEGF, eNOS, and $\mathrm{ABCB} 1$ genetic polymorphisms may increase the risk of osteonecrosis of the femoral head. Genet Mol Res 2015;14:13688-98.

11. Maheshwari PR, Nagar AM, Prasad SS, Shah JR, Patkar DP. Avascular necrosis of spine: a rare appearance. Spine (Phila Pa 1976) 2004;29:E119-22.

12. Prakash, Prabhu LV, Saralaya VV, et al. Vertebral body integrity: a review of various anatomical factors involved in the lumbar region. Osteoporos Int 2007;18:891-903.

13. Stojanovic J, Kovac V. Diagnosis of ischemic vertebral collapse using selective spinal angiography. Rofo 1981;135:326-9.

14. Ratcliffe JF. The arterial anatomy of the adult human lumbar vertebral body: a microarteriographic study. J Anat 1980;131(Pt 1):57-79.

15. Kim HW, Kwon A, Lee MC, Song JW, Kim SK, Kim IH. Analysis of results using percutaneous vertebroplasty for the treatment of avascular necrosis of the vertebral body. J Korean Neurosurg Soc 2009;45:20912.

16. Modena V, Maiocco I, Bosio C, Bianchi A, DeFilippi PG, Daneo V. Intravertebral vacuum cleft: notes on five cases. Clin Exp Rheumatol 1985;3:23-7.

17. Martin-Esteve I, Aparicio-Espinar M, HernandezGanan J, Narvaez J. Vertebral osteonecrosis as a complication of corticosteroid therapy: the intravertebral vacuum cleft sign. Reumatol Clin 2012;8:375-7. 
18. Jang JS, Kim DY, Lee SH. Efficacy of percutaneous vertebroplasty in the treatment of intravertebral pseudarthrosis associated with noninfected avascular necrosis of the vertebral body. Spine (Phila Pa 1976) 2003;28:1588-92.

19. Lee SH, Kim ES, Eoh W. Cement augmented anterior reconstruction with short posterior instrumentation: a less invasive surgical option for Kummell's disease with cord compression. J Clin Neurosci 2011;18:50914.

20. Kim SW, Kim HS. A case of posterior element fracture in Kummell's disease. Osteoporos Int 2012;23:1641-4.

21. Kim YC, Kim YH, Ha KY. Pathomechanism of intravertebral clefts in osteoporotic compression fractures of the spine. Spine J 2014;14:659-66.

22. Chen L, Dong R, Gu Y, Feng Y. Comparison between balloon kyphoplasty and short segmental fixation combined with vertebroplasty in the treatment of Kummell's disease. Pain Physician 2015;18:373-81.

23. Park SJ, Kim HS, Lee SK, Kim SW. Bone cementaugmented percutaneous short segment fixation: an effective treatment for Kummell's disease? J Korean Neurosurg Soc 2015;58:54-9.

24. Jindal N, Sharma R, Jindal R, Garg SK. Literature update and challenges ahead. Hard Tissue 2013;2:45.

25. Brower AC, Downey EF Jr. Kummell disease: report of a case with serial radiographs. Radiology 1981;141:363-4.

26. Chou LH, Knight RQ. Idiopathic avascular necrosis of a vertebral body: case report and literature review. Spine (Phila Pa 1976) 1997;22:1928-32.

27. Mirovsky Y, Anekstein Y, Shalmon E, Peer A. Vacuum clefts of the vertebral bodies. AJNR Am J Neuroradiol 2005;26:1634-40.

28. Fabbriciani G, Pirro M, Floridi P, et al. Osteoanabolic therapy: a non-surgical option of treatment for Kummell's disease? Rheumatol Int 2012;32:1371-4.

29. Young WF, Brown D, Kendler A, Clements D. Delayed post-traumatic osteonecrosis of a vertebral body (Kummell's disease). Acta Orthop Belg 2002;68:13-9.

30. Malzer U, Pfeiffer M, Griss P. Posttraumatic vertebral body necrosis (Kummell-Verneuil disease): case report of a rare orthopaedic disease with histopathological correlation. Eur Spine J 1992;1:55-9.

31. Ma R, Chow R, Shen FH. Kummell's disease: delayed post-traumatic osteonecrosis of the vertebral body. Eur Spine J 2010;19:1065-70.

32. Swartz K, Fee D. Kummell's disease: a case report and literature review. Spine (Phila Pa 1976) 2008;33:E1525.

33. Steel HH. Kummell's disease. Am J Surg 1951;81:1617.

34. Rigler L. Kummell's disease with report of a roentgenologically proved case. Am J Roentgenol 1931;35:749-53.

35. Hutter CD. Dysbaric osteonecrosis: a reassessment and hypothesis. Med Hypotheses 2000;54:585-90.

36. Allen BL Jr, Jinkins WJ 3rd. Vertebral osteonecrosis associated with pancreatitis in a child: a case report. J Bone Joint Surg Am 1978;60:985-7.

37. Baba T, Shitoto K, Yoshioka C, Kaneko H. Pathological fracture due to vertebral osteonecrosis associated with pancreatitis. Arch Orthop Trauma Surg 2011;131:11-4.

38. Van Eenenaam DP, el-Khoury GY. Delayed posttraumatic vertebral collapse (Kummell's disease): case report with serial radiographs, computed tomographic scans, and bone scans. Spine (Phila Pa 1976) 1993;18:1236-41.

39. Wang F, Wang D, Tan B, et al. Comparative study of modified posterior operation to treat Kummell's disease. Medicine (Baltimore) 2015;94:e1595.

40. Osterhouse MD, Kettner NW. Delayed posttraumatic vertebral collapse with intravertebral vacuum cleft. J Manipulative Physiol Ther 2002;25:270-5.

41. Golimbu C, Firooznia H, Rafii M. The intravertebral vacuum sign. Spine (Phila Pa 1976) 1986;11:1040-3.

42. Hermann G, Goldblatt J, Desnick RJ. Kummell disease: delayed collapse of the traumatised spine in a patient with Gaucher type 1 disease. Br J Radiol 1984;57:833-5.

43. Poll LW, Willers R, Haussinger D, Modder U, vom Dahl S. MRI bone marrow findings in 63 patients with type I Gaucher disease. Rofo 2010;182:979-85.

44. Lin CL, Lin RM, Huang KY, Yan JJ, Yan YS. MRI fluid sign is reliable in correlation with osteonecrosis after vertebral fractures: a histopathologic study. Eur Spine J 2013;22:1617-23.

45. Sarli M, Perez Manghi FC, Gallo R, Zanchetta JR. The vacuum cleft sign: an uncommon radiological sign. Osteoporos Int 2005;16:1210-4.

46. Ito M, Motomiya M, Abumi K, et al. Vertebral osteo- 
necrosis associated with sarcoidosis: case report. J Neurosurg Spine 2005;2:222-5.

47. Nickell LT, Schucany WG, Opatowsky MJ. Kummell disease. Proc (Bayl Univ Med Cent) 2013;26:300-1.

48. Mitchell DG, Kressel HY, Arger PH, Dalinka M, Spritzer CE, Steinberg ME. Avascular necrosis of the femoral head: morphologic assessment by MR imaging, with CT correlation. Radiology 1986;161:739-42.

49. Maldague BE, Noel HM, Malghem JJ. The intravertebral vacuum cleft: a sign of ischemic vertebral collapse. Radiology 1978;129:23-9.

50. Theodorou DJ. The intravertebral vacuum cleft sign. Radiology 2001;221:787-8.

51. Bhalla S, Reinus WR. The linear intravertebral vacuum: a sign of benign vertebral collapse. AJR Am J Roentgenol 1998;170:1563-9.

52. Lane JI, Maus TP, Wald JT, Thielen KR, Bobra S, Luetmer PH. Intravertebral clefts opacified during vertebroplasty: pathogenesis, technical implications, and prognostic significance. AJNR Am J Neuroradiol 2002;23:1642-6.

53. Kumpan W, Salomonowitz E, Seidl G, Wittich GR. The intravertebral vacuum phenomenon. Skeletal Radiol 1986;15:444-7.

54. Chen LH, Lai PL, Niu CC, Chen CH, Chen WJ, Fu TS. Intracorporal bone grafting for vertebral compression fractures with intraosseous vacuum phenomenon. Int Orthop 2004;28:52-5.

55. Wu AM, Chi YL, Ni WF. Vertebral compression fracture with intravertebral vacuum cleft sign: pathogenesis, image, and surgical intervention. Asian Spine J 2013;7:148-55

56. Libicher M, Appelt A, Berger I, et al. The intravertebral vacuum phenomen as specific sign of osteonecrosis in vertebral compression fractures: results from a radiological and histological study. Eur Radiol 2007;17:2248-52.

57. Fang X, Yu F, Fu S, Song H. Intravertebral clefts in osteoporotic compression fractures of the spine: incidence, characteristics, and therapeutic efficacy. Int J Clin Exp Med 2015;8:16960-8.

58. McKiernan F, Faciszewski T. Intravertebral clefts in osteoporotic vertebral compression fractures. Arthritis Rheum 2003;48:1414-9.

59. Feng SW, Chang MC, Wu HT, Yu JK, Wang ST, Liu CL. Are intravertebral vacuum phenomena benign lesions? Eur Spine J 2011;20:1341-8.
60. Lafforgue P, Chagnaud C, Daumen-Legre V, Daver L, Kasbarian M, Acquaviva PC. The intravertebral vacuum phenomenon ("vertebral osteonecrosis"): migration of intradiscal gas in a fractured vertebral body? Spine (Phila Pa 1976) 1997;22:1885-91.

61. Armingeat T, Pham T, Legre V, Lafforgue P. Coexistence of intravertebral vacuum and intradiscal vacuum. Joint Bone Spine 2006;73:428-32.

62. Yu CW, Hsu CY, Shih TT, Chen BB, Fu CJ. Vertebral osteonecrosis: MR imaging findings and related changes on adjacent levels. AJNR Am J Neuroradiol 2007;28:42-7.

63. Kim H, Jun S, Park SK, Kim GT, Park SH. Intravertebral vacuum cleft sign: a cause of vertebral cold defect on bone scan. Skeletal Radiol 2016;45:707-12.

64. Murakami H, Kawahara N, Gabata T, Nambu K, Tomita K. Vertebral body osteonecrosis without vertebral collapse. Spine (Phila Pa 1976) 2003;28:E323-8.

65. Naul LG, Peet GJ, Maupin WB. Avascular necrosis of the vertebral body: MR imaging. Radiology 1989;172:219-22.

66. Ranjan M, Mahadevan A, Prasad C, Sommana S, Susarla Krishna S. Kummell's disease: uncommon or underreported disease: a clinicopathological account of a case and review of literature. J Neurosci Rural Pract 2013;4:439-42.

67. Baur A, Stabler A, Arbogast S, Duerr HR, Bartl R, Reiser M. Acute osteoporotic and neoplastic vertebral compression fractures: fluid sign at MR imaging. Radiology 2002;225:730-5.

68. Linn J, Birkenmaier C, Hoffmann RT, Reiser M, Baur-Melnyk A. The intravertebral cleft in acute osteoporotic fractures: fluid in magnetic resonance imaging-vacuum in computed tomography? Spine (Phila Pa 1976) 2009;34:E88-93.

69. Dupuy DE, Palmer WE, Rosenthal DI. Vertebral fluid collection associated with vertebral collapse. AJR Am J Roentgenol 1996;167:1535-8.

70. Formica M, Basso M, Cavagnaro L, Formica C, Zanirato A, Felli L. Kummell disease: illustrative case for definition criteria. Spine J 2016;16:e707-8.

71. Van der Schaaf I, Fransen H. Percutaneous vertebroplasty as treatment for Kummell's disease. JBR-BTR 2009;92:83-5.

72. Malghem J, Maldague B, Labaisse MA, et al. Intravertebral vacuum cleft: changes in content after supine positioning. Radiology 1993;187:483-7. 
73. Niu J, Song D, Zhou H, Meng Q, Meng B, Yang H. Percutaneous kyphoplasty for the treatment of osteoporotic vertebral fractures with intravertebral fluid or air: a comparative study. Clin Spine Surg 2017;30:367-73.

74. Formica M, Zanirato A, Cavagnaro L, et al. Vertebral body osteonecrosis: proposal of a treatment-oriented classification system. Eur Spine J 2018 Apr 16 [Epub]. https://10.1007/s00586-018-5600-6.

75. Garbossa D, Pejrona M, Damilano M, Sansone V, Ducati A, Berjano P. Pelvic parameters and global spine balance for spine degenerative disease: the importance of containing for the well being of content. Eur Spine J 2014;23 Suppl 6:616-27.

76. Lamartina C, Berjano P. Classification of sagittal imbalance based on spinal alignment and compensatory mechanisms. Eur Spine J 2014;23:1177-89.

77. Lamartina C, Berjano P, Petruzzi M, et al. Criteria to restore the sagittal balance in deformity and degenerative spondylolisthesis. Eur Spine J 2012;21 Suppl 1:S27-31.

78. Rossini M, Viapiana O, Gatti D, de Terlizzi F, Adami S. Capacitively coupled electric field for pain relief in patients with vertebral fractures and chronic pain. Clin Orthop Relat Res 2010;468:735-40.

79. Masala S, Nano G, Mammucari M, Simonetti G. Kummel disease treatment by unipedicular vertebral augmentation using curved injection cannula. Cardiovasc Intervent Radiol 2011;34:1014-20.

80. Do HM, Jensen ME, Marx WF, Kallmes DF. Percutaneous vertebroplasty in vertebral osteonecrosis (Kummell's spondylitis). Neurosurg Focus 1999;7:e2.

81. Peh WC, Gelbart MS, Gilula LA, Peck DD. Percutaneous vertebroplasty: treatment of painful vertebral compression fractures with intraosseous vacuum phenomena. AJR Am J Roentgenol 2003;180:1411-7.

82. Yang H, Gan M, Zou J, et al. Kyphoplasty for the treatment of Kummell's disease. Orthopedics 2010;33:479.

83. Hirsch JA, Reddy AS, Linfante I, Rachlin JR. PseudoKummel's disease: a unique application for vertebroplasty. Pain Physician 2003;6:207-11.

84. Huang Y, Peng M, He S, Tang X, Dai M, Tang C. Clinical efficacy of percutaneous kyphoplasty at the hyperextension position for the treatment of osteoporotic Kummell disease. Clin Spine Surg 2016;29:161-6.

85. Chen GD, Lu Q, Wang GL, et al. Percutaneous ky- phoplasty for Kummell disease with severe spinal canal stenosis. Pain Physician 2015;18:E1021-8.

86. Kim DY, Lee SH, Jang JS, Chung SK, Lee HY. Intravertebral vacuum phenomenon in osteoporotic compression fracture: report of 67 cases with quantitative evaluation of intravertebral instability. J Neurosurg 2004;100(1 Suppl Spine):24-31.

87. Hur W, Choi SS, Lee M, Lee DK, Lee JJ, Kim K. Spontaneous vertebral reduction during the procedure of kyphoplasty in a patient with Kummell's Disease. Korean J Pain 2011;24:231-4.

88. Zhang GQ, Gao YZ, Chen SL, Ding S, Gao K, Wang HQ. Comparison of percutaneous vertebroplasty and percutaneous kyphoplasty for the management of Kummell's disease: a retrospective study. Indian J Orthop 2015;49:577-82.

89. Krauss M, Hirschfelder H, Tomandl B, Lichti G, Bar I. Kyphosis reduction and the rate of cement leaks after vertebroplasty of intravertebral clefts. Eur Radiol 2006;16:1015-21.

90. Nieuwenhuijse MJ, van Erkel AR, Dijkstra PD. Cement leakage in percutaneous vertebroplasty for osteoporotic vertebral compression fractures: identification of risk factors. Spine J 2011;11:839-48.

91. Ha KY, Lee JS, Kim KW, Chon JS. Percutaneous vertebroplasty for vertebral compression fractures with and without intravertebral clefts. J Bone Joint Surg Br 2006;88:629-33.

92. Tanigawa N, Kariya S, Komemushi A, et al. Cement leakage in percutaneous vertebroplasty for osteoporotic compression fractures with or without intravertebral clefts. AJR Am J Roentgenol 2009;193:W442-5.

93. Wu AM, Ni WF, Weng W, Chi YL, Xu HZ, Wang XY. Outcomes of percutaneous kyphoplasty in patients with intravertebral vacuum cleft. Acta Orthop Belg 2012;78:790-5.

94. Jung JY, Lee MH, Ahn JM. Leakage of polymethylmethacrylate in percutaneous vertebroplasty: comparison of osteoporotic vertebral compression fractures with and without an intravertebral vacuum cleft. J Comput Assist Tomogr 2006;30:501-6.

95. Heo DH, Choi JH, Kim MK, et al. Therapeutic efficacy of vertebroplasty in osteoporotic vertebral compression fractures with avascular osteonecrosis: a minimum 2-year follow-up study. Spine (Phila $\mathrm{Pa}$ 1976) 2012;37:E423-9.

96. Zhang GQ, Gao YZ, Zheng J, et al. Posterior decom- 
pression and short segmental pedicle screw fixation combined with vertebroplasty for Kummell's disease with neurological deficits. Exp Ther Med 2013;5:51722.

97. Lee GW, Yeom JS, Kim HJ, Suh BG. A therapeutic efficacy of the transpedicular intracorporeal bone graft with short-segmental posterior instrumentation in osteonecrosis of vertebral body: a minimum 5-year follow-up study. Spine (Phila Pa 1976) 2013;38:E244-50.

98. Li KC, Li AF, Hsieh CH, Liao TH, Chen CH. Another option to treat Kummell's disease with cord compression. Eur Spine J 2007;16:1479-87.

99. Formica M, Cavagnaro L, Basso M, et al. Which patients risk segmental kyphosis after short segment thoracolumbar fracture fixation with intermediate screws? Injury 2016;47 Suppl 4:S29-S34.

100. Matzaroglou C, Georgiou CS, Assimakopoulos K, Saridis A, Khudiaev AT, Giannakenas C. Kummell' $s$ disease: a rare spine entity in a young adult. Hell $\mathrm{J}$ Nucl Med 2010;13:52-5.

101. Berjano P, Lamartina C. Classification of degenerative segment disease in adults with deformity of the lumbar or thoracolumbar spine. Eur Spine J 2014;23:1815-24.
102. Zhang X, Hu W, Yu J, Wang Z, Wang Y. An effective treatment option for Kummell disease with neurological deficits: modified transpedicular subtraction and disc osteotomy combined with long-segment fixation. Spine (Phila Pa 1976) 2016;41:E923-30.

103. Lee JH, Kim KT, Suk KS, Lee SH, Jeong BO. Avascular necrosis of the spine in solid posterior fusion segments. Spine (Phila Pa 1976) 2009;34:E158-61.

104. Sciubba DM, Yurter A, Smith JS, et al. A comprehensive review of complication rates after surgery for adult deformity: a reference for informed consent. Spine Deform 2015;3:575-94.

105. Formica M, Cavagnaro L, Zanirato A, Felli L, Formica C. Proximal junctional spondylodiscitis after pedicle subtraction osteotomy. Spine J 2016;16:e4951.

106. Cho SM, Heo DH, Cho YJ. Spontaneous migration of a polymethylmethacrylate mass after vertebroplasty in osteoporotic lumbar compression fracture with avascular osteonecrosis: a case report. Joint Bone Spine 2011;78:98-9. 